\title{
Comparison of automated and manual protocols for magnetic resonance imaging assessment of liver iron concentration
}

\author{
Comparação de protocolos automatizados e manuais de ressonância magnética para avaliação \\ da concentração hepática de ferro

\section{Izabella de Campos Carvalho Lopes ${ }^{1, a}$, Manuel Schütze ${ }^{1, b}$, Marina Borges Bolina ${ }^{1, c}$, Tarcísio Ângelo de Oliveira Sobrinho $^{1, \mathrm{~d}}$, Laura Filgueiras Mourão Ramos ${ }^{1, \mathrm{e}}$, Renata Lopes Furletti Caldeira Diniz ${ }^{1, \mathrm{f}}$, Juliano Lara Fernandes ${ }^{2, \mathrm{~g}}$, Maria Helena Albernaz Siqueira ${ }^{1, h}$}

\begin{abstract}
1. Radiology and Diagnostic Imaging, Hospital Mater Dei, Pós-Graduação Ciências Médicas de Minas Gerais (PGCM-MG), Belo Horizonte, MG, Brazil. 2. Cardiovascular Imaging Center, Jose Michel Kalaf Research Institute, Campinas, SP, Brazil.

Correspondence: Dra. Izabella de Campos Carvalho Lopes. Radiologia e Diagnóstico por Imagem, Hospital Mater Dei. Rua Gonçalves Dias, 2700 , Santo Agostinho. Belo Horizonte, MG, Brazil, 30190-094. Email: izabellaccl@gmail.com.

a. https://orcid.org/0000-0001-9735-219x; b. https://orcid.org/0000-0003-1947-9675; c. https://orcid.org/0000-0002-8714-5338; d. https://orcid.org/0000-0003-1877-1041; e. https://orcid.org/0000-0003-4201-0525; f. https://orcid.org/0000-0002-7008-8066; g. https://orcid.org/0000-0002-6726-5324; h. https://orcid.org/0000-0003-3048-650X.

Received 19 February 2019. Accepted after revision 12 September 2019.
\end{abstract}

How to cite this article:

Lopes ICC, Schütze M, Bolina MB, Oliveira Sobrinho TA, Ramos LFM, Diniz RLFC, Fernandes JL, Siqueira MHA. Comparison of automated and manual protocols for magnetic resonance imaging assessment of liver iron concentration. Radiol Bras. 2020 Mai/Jun;53(3):148-154.

Abstract Objective: To compare automated and manual magnetic resonance imaging protocols for estimating liver iron concentrations at $1.5 \mathrm{~T}$. Materials and Methods: Magnetic resonance imaging examination of the liver was performed in 53 patients with clinically suspected hepatic iron overload and in 21 control subjects. Liver iron concentrations were then estimated by two examiners who were blinded to the groups. The examiners employed automated T2* and T1 mapping, as well as manual T2* and signal-intensity-ratio method. We analyzed accuracy by using ROC curves. Interobserver and intraobserver agreement were analyzed by calculating twoway intraclass correlation coefficients.

Results: The area under the ROC curve (to discriminate between patients and controls) was 0.912 for automated T2* mapping, 0.934 for the signal-intensity-ratio method, 0.908 for manual T2*, and 0.80 for T1 mapping, the last method differing significantly from the other three. The level of interobserver and intraobserver agreement was good (intraclass correlation coefficient, 0.9380.998; $p<0.05$ ). Correlations involving T1 mapping, although still significant, were lower.

Conclusion: At 1.5 T, T2* mapping is a rapid tool that shows promise for the diagnosis of liver iron overload, whereas T1 mapping shows less accuracy. The performance of T1 mapping is poorer than is that of T2* methods.

Keywords: Liver/diagnostic imaging; Liver/metabolism; Iron overload/diagnostic imaging; Iron/metabolism; Magnetic resonance imaging/methods; Image processing, computer-assisted/methods.

Res u mo Objetivo: Comparar protocolos automatizados e manuais de ressonância magnética para estimar a concentração hepática de ferro em 1,5 T.

Materiais e Métodos: Foi realizada ressonância magnética hepática em 53 pacientes com suspeita de sobrecarga de ferro hepática e 21 controles, seguida da estimativa cega da concentração hepática de ferro por dois examinadores usando mapas automáticos T2* e T1, assim como o manual T2* e o método signal-intensity-ratio. 0 desempenho foi medido usando curvas ROC e a correlação interobservador e intraobservador usando o coeficiente de correlação intraclasse bidirecional.

Resultados: 0 desempenho da curva ROC separando pacientes e controles mostrou áreas sob a curva de 0,912 para o mapa automático T2*, 0,934 para o método signal-intensity-ratio, 0,908 para manual T2* e 0,80 para mapa T1 (este difere significativamente dos outros três métodos). Houve boa correlação interobservador e intraobservador (coeficiente de correlação intraclasse entre 0,938 e 0,998; $p$ < 0,05). Correlações envolvendo o mapa T1, embora ainda significativas, foram menores.

Conclusão: Em 1,5 T, o mapa T2* representa uma nova ferramenta rápida e promissora para avaliar o diagnóstico de sobrecarga de ferro hepática, enquanto o mapa T1 mostrou menor precisão. 0 desempenho do mapa T1 foi menor que o dos métodos T2*.

Unitermos: Fígado/diagnóstico por imagem; Fígado/metabolismo; Sobrecarga de ferro/diagnóstico por imagem; Ferro/metabolismo; Ressonância magnética/métodos; Processamento de imagem assistida por computador/métodos.

\section{INTRODUCTION}

Iron overload usually results from chronic blood transfusion therapy for any one of several types of ane$\mathrm{mia}^{(1-3)}$ or disorders of iron absorption such as hereditary hemochromatosis $^{(2,4)}$.
Because the liver accounts for more than $70 \%$ of somatic iron storage ${ }^{(1,2)}$, the liver iron concentration (LIC) is an excellent surrogate marker for the whole-body iron $\operatorname{load}^{(1,3,5)}$, as well as helping predict the risk of intrahepatic and extrahepatic complications ${ }^{(3)}$. 
Biochemical analysis of a liver biopsy is the gold standard for the measurement of $\mathrm{LIC}^{(3-8)}$ and is expressed as either $\mathrm{mg} / \mathrm{g}$ liver (dry weight), with a maximum normal value of $2 \mathrm{mg} / \mathrm{g}$, or as $\mu \mathrm{mol} / \mathrm{g}$, with a maximum normal value of $36 \mu \mathrm{mol} / \mathrm{g}^{(9)}$. However, because liver biopsy is an invasive method, magnetic resonance imaging (MRI) is chosen as the method for LIC measurement with everincreasing frequency ${ }^{(3-9)}$. MRI emerged as the dominant modality for LIC measurement because of its sensitivity, reproducibility, availability, and ability to evaluate multiple organs of the body during a single imaging $\operatorname{session}^{(3,5,7,10)}$. MRI quantifies iron indirectly by detecting the paramagnetic effects of iron stores in the forms of ferritin and hemosiderin, interacting with nearby hydrogen nuclei. A number of empirical MRI methods for the determination of tissue iron overload have been proposed ${ }^{(6)}$. This has been traditionally done using manual methods, which are well-established and are validated and calibrated against the gold standard of liver biopsy, but are more user dependent and take more time to perform. More recently though, automatic methods have been proposed, with the advantage of speed and ease of use. The aim of this study was to compare automated and manual MRI protocols for estimating LIC at $1.5 \mathrm{~T}$.

\section{MATERIALS AND METHODS}

\section{Study design and population}

This was a prospective single-center study of patients who were referred to our department for liver MRI because of suspected hepatic iron overload. We included patients with an elevated serum ferritin level $(>300 \mu \mathrm{g} / \mathrm{L}$ in male patients and $>200 \mu \mathrm{g} / \mathrm{L}$ in female patients) or elevated transferrin saturation $(>45 \%$ in male patients and $>50 \%$ in female patients). Thus, 60 eligible patients were identified. Subjects with the following conditions were excluded from the study: claustrophobia $(\mathrm{n}=2)$; inability to consent $(n=1)$; and liver nodules detected on MRI $(n=4)$. Therefore, the final study group comprised 53 patients. We also evaluated 21 healthy controls, selected by convenience, with no history of liver or metabolic disease. All examinations were performed between October 2014 and August 2017. Age, gender, and body mass index were recorded for patients and controls. The study was approved by the local research ethics committee, and all participants gave written informed consent.

\section{MRI techniques}

Unenhanced images were acquired in a $1.5 \mathrm{~T}$ scanner (Magnetom Avanto; Siemens Healthcare, Erlangen, Germany), with a body coil and dedicated software, version syngo MR B17. For the signal-intensity-ratio method proposed by the University of Rennes (URennes), we acquired five axial gradient-echo (GRE) sequences of the liver with a repetition time (TR) of $120 \mathrm{~ms}$. A typical T1-weighted sequence-with an in-phase echo time (TE) of $4 \mathrm{~ms}$ and a flip angle of $90^{\circ}$ - was followed by four sequences with a standard flip angle of $20^{\circ}$ and progressively increasing T2-weighting-in-phase TE increasing from 4 to 21 $\mathrm{ms}^{(4,6,11,12)}$. For the manual $\mathrm{T} 2$ * protocol, a multi-echo GRE (mGRE) sequence was used in order to acquire 12 images with increasing TE (range, 1.3-16.9 ms, with 1.4 ms intervals), a TR of $200 \mathrm{~ms}$, a flip angle of $20^{\circ}$, a field of view of $400 \times 400 \mathrm{~mm}^{2}$, a matrix of 96-128 $\times 64-96$, and a slice thickness of $10 \mathrm{~mm}^{(10)}$.

Automated $\mathrm{T} 2 *$ and $\mathrm{T} 1$ maps were generated by inline processing prototype software, the same used in the All Iron Detected Multicenter Study ${ }^{(13)}$. Acquisition of mGRE sequences with radiofrequency spoiling was used in order to create the $\mathrm{T} 2{ }^{*} \operatorname{map}^{(14-16)}$. The $\mathrm{T} 1$ map was acquired by using a modified look-locker inversion recovery (MOLLI) sequence with the 5(3)3 protocol $^{(14,17,18)}$.

\section{Liver MRI analysis}

Data were analyzed by two radiologists (with ten and three years of experience in abdominal radiology, respectively), both of whom were blinded to the clinical status of the subjects, and the level of interobserver agreement was assessed. One of the radiologists also repeated all measurements, in order to allow intraobserver agreement to be assessed.

Four methods for estimating LIC values were evaluated in this study. The two manual methods were well-established at the time of the study design: the URennes (signal-intensity-ratio) method proposed by Gandon et al. ${ }^{(11)}$; and the manual $\mathrm{T}^{*}$ (relaxometry) method proposed by Hankins et al. ${ }^{(10)}$. Both have been validated and calibrated against the gold standard of liver biopsy and show that MRI enables good quantification of LIC $^{(10-12,19-25)}$. The two automatic methods evaluated were the ultrafast scanning $\mathrm{T}^{*}$ and $\mathrm{T} 1$ mapping techniques ${ }^{(13-18)}$, which were proposed more recently

\section{URennes method}

For quantification of the URennes values, we used the algorithm developed by Gandon et al. ${ }^{(11)}$. That algorithm uses the liver-to-muscle signal intensity ratios in five axial GRE sequences of the liver. For every sequence, we measured liver signal intensity (SI) in three operator-defined regions of interest (ROIs) of $1-3 \mathrm{~cm}^{2}$ in the right lobe of the liver, avoiding large vessels, biliary tracts, parenchymatous lesions, and artifacts. Muscle SI was measured in two ROIs in the right and left paraspinal muscles. The ROIs were propagated to all five images. Values were entered manually on a website developed by the authors ${ }^{(12)}$, which provides $\mathrm{LIC}$ values in $\mu \mathrm{mol} \mathrm{Fe} / \mathrm{g}$.

\section{Manual T2* mapping}

We drew freehand ROIs directly on the scanner console over source images in a homogeneous area of the right hepatic lobe, at the level of the origin of the main portal 
vein, avoiding blood vessels and visible bile ducts. The SI was obtained and transferred manually to the software on another computer. The mean SI in each slice with varying TEs was used in order to fit the $\mathrm{T} 2 *$ curve by using the formula $S I=K e^{-T 2^{*} / T E}$, with truncation of the decay curve to achieve the best results, in accordance with previous recommendations ${ }^{(10)}$. The TEs were manually excluded from the fit in images with high iron-mediated signal loss.

The $\mathrm{T}^{*}$ values were transformed into their reciprocal R2* $(\mathrm{R} 2 *[\mathrm{~Hz}]=1,000 / \mathrm{T} 2 *[\mathrm{~ms}])$. The LIC values (in $\mathrm{mg} \mathrm{Fe} / \mathrm{g}$ ) were estimated from $\mathrm{R} 2 *$ values using the linear regression model described by Hankins et al. ${ }^{(10)}$.

\section{T2* mapping}

Automated $\mathrm{T}^{*}$ maps were calculated using in-line processing prototype software and were based on the original mGRE images of the liver. The $\mathrm{T} 2 *$ values (in ms) were obtained by drawing an ROI directly onto the map generated $^{(13-16)}$. The LIC values (in $\mathrm{mg} \mathrm{Fe} / \mathrm{g}$ ) were estimated by using the linear regression model described by Hankins et al. ${ }^{(10)}$.

\section{T1 mapping}

The T1 map was measured in six circular ROIs larger than $1 \mathrm{~cm}^{2}$ (range, $1-3 \mathrm{~cm}^{2}$ ). We placed four ROIs in the right lobe and two in the left lobe, avoiding artifacts, major vascular structures, and lesions. The prototype software generated a native image with multiple echoes, as well as final T1 maps that had already been processed automatically ${ }^{(14,17,18)}$. In our calculations, we used the arithmetic mean of those ROIs. The T1 values were transformed into their reciprocal $\mathrm{R} 1$ values $(\mathrm{R} 1[\mathrm{~Hz}]=1000 / \mathrm{T} 1[\mathrm{~ms}])$, which increase during iron overload. It was not possible to estimate LIC values based on R1, because there is as yet no conversion formula for those two measures.

\section{Statistical analysis}

For the calculation of descriptive statistics, numerical variables were submitted to the Shapiro-Wilk test of normality. Those variables are presented as mean \pm standard deviation (SD) when normally distributed and as median (interquartile range) when not. Categorical variables are presented as frequencies and percentages. We compared patients and control subjects using the t-test for normally distributed variables or the Mann-Whitney-Wilcoxon test for those not so distributed. Categorical values were compared by the chi-square test.

Measures obtained with the URennes, manual T2*, automated T2* mapping, and T1 mapping protocols were compared by constructing receiver operating characteristic (ROC) curves, and the performance of the protocols was assessed by calculating the area under the curve (AUC) and the corresponding 95\% confidence interval (95\% CI). Correlations between measures were quantified by calculating Spearman's correlation coefficient. The intraclass correlation coefficient (ICC) was calculated in order to determine the level of interobserver and intraobserver agreement ${ }^{(26)}$, and the Student's t-test for independent samples (difference equal to zero) was used for the analysis of differences between means. Statistical analyses were performed with R software, version 3.3.2 (R Foundation for Statistical Computing, Vienna, Austria). Values of $p<0.05$ were considered statistically significant.

\section{RESULTS}

\section{Sample characteristics}

In this study, we assessed LICs in 74 individuals (53 patients and 21 controls). The subject characteristics are summarized in Table 1. Patients did not differ significantly from healthy control subjects with respect to gender, age, height, or the presence of hepatic steatosis. However, the control subjects had lower body weights $(p<0.001)$. Among the patients, the mean serum ferritin was $974 \mu \mathrm{g} / \mathrm{L}$ in the males and $1542 \mu \mathrm{g} / \mathrm{L}$ in the females.

Table 1-Characteristics of the subjects evaluated.

\begin{tabular}{|c|c|c|c|c|}
\hline \multirow[b]{2}{*}{ Characteristic } & \multirow[b]{2}{*}{$\begin{array}{l}\text { All subjects } \\
\quad(n=74)\end{array}$} & \multicolumn{2}{|c|}{ Group } & \multirow[b]{2}{*}{$P$-value } \\
\hline & & $\begin{array}{l}\text { Patients } \\
(n=53)\end{array}$ & $\begin{array}{l}\text { Controls } \\
(n=21)\end{array}$ & \\
\hline Male gender, n (\%) & 35 (47.3) & $23(43.4)$ & 12 (57.1) & $0.418 *$ \\
\hline Age (years), mean \pm SD & $36.5 \pm 29$ & $33 \pm 30$ & $41 \pm 36$ & $0.084^{\dagger}$ \\
\hline Weight (kg), mean \pm SD & $67.6 \pm 25.3$ & $62.0 \pm 25.7$ & $81.6 \pm 17.9$ & $<0.001^{\ddagger}$ \\
\hline Height $(m)$, mean \pm SD & $165.5 \pm 15$ & $165 \pm 20$ & $170 \pm 8$ & $0.096^{\dagger}$ \\
\hline Steatosis, n (\%) & $18(24.3)$ & $12(22.6)$ & $6(28.6)$ & $0.814 *$ \\
\hline \multicolumn{5}{|l|}{ Diagnoses, $n^{\S}(\%)$} \\
\hline Sick-cell disease & $28(37.8)$ & $28(52.8)$ & - & - \\
\hline Hemochromatosis & $11(14.9)$ & $11(20.8)$ & - & - \\
\hline Hyperferritinemia & $10(13.5)$ & $10(18.9)$ & - & - \\
\hline Thalassemia major & $3(4.1)$ & $3(5.7)$ & - & - \\
\hline Thalassemia intermedia & $3(4.1)$ & $3(5.7)$ & - & - \\
\hline Thalassemia minor & $1(1.4)$ & $1(1.9)$ & - & - \\
\hline
\end{tabular}

* Chi-square test of independence.

${ }^{\dagger}$ Mann-Whitney-Wilcoxon test-data as median (interquartile range).

‡Student’s t-test for independent samples-data as mean \pm SD.

$\S$ Two patients had sickle-cell disease and hemochromatosis, and one patient had sickle-cell disease and thalassemia major.

\section{Reliability of the measures}

The interobserver analysis showed no significant difference between the two radiologists, with excellent agreement between the measurements (Table 2). Because the agreement between the two raters for all methods was high, correlation and ROC curve analyses were performed using the measures obtained by the first rater. The intraobserver analysis showed no significant difference between repeated measures by the same radiologist for all of the methods, except for T1 mapping $(p<0.05)$, despite the fact that the ICC for agreement between the two raters was above 0.9 for all of the protocols (Table 2). 
Table 2-Interobserver and intraobserver agreement for all of the methods evaluated.

\begin{tabular}{|c|c|c|c|c|}
\hline \multirow[b]{3}{*}{ Protocol } & \multicolumn{4}{|c|}{ Agreement } \\
\hline & \multicolumn{2}{|c|}{ Interobserver } & \multicolumn{2}{|c|}{ Intraobserver } \\
\hline & Mean difference $(95 \% \mathrm{Cl})$ & ICC (95\% Cl) & Mean difference $(95 \% \mathrm{Cl})$ & $\operatorname{ICC}(95 \% \mathrm{Cl})$ \\
\hline URennes & $-0.012(-0.115$ to 0.090$)$ * & $0.998(0.996 \text { to } 0.999)^{\dagger}$ & $0.057(-0.240 \text { to } 0.353)^{*}$ & $0.986(0.976 \text { to } 0.992)^{\dagger}$ \\
\hline T2* mapping & $0.016(-0.142$ to 0.174$)$ * & $0.980(0.969 \text { to } 0.988)^{\dagger}$ & $0.082(-0.041 \text { to } 0.206)^{*}$ & $0.987(0.980 \text { to } 0.992)^{\dagger}$ \\
\hline T1 mapping & $-3.878(-10.745$ to 2.988$)$ * & $0.964(0.944 \text { to } 0.977)^{\dagger}$ & $-10.095(-19.170 \text { to }-1.019)^{\dagger}$ & $0.938(0.903 \text { to } 0.960)^{\dagger}$ \\
\hline Manual T2* & $0.007(-0.227$ to 0.241$) *$ & $0.954(0.927 \text { to } 0.970)^{\dagger}$ & $0.009(-0.215$ to 0.233$)$ * & $0.957(0.933 \text { to } 0.973)^{\dagger}$ \\
\hline
\end{tabular}

$\star P>0.05$ by Student's t-test for independent samples (difference equal to zero).

$+P<0.05$

\section{Performance of the protocols}

The scan times and average image analysis durations are listed in Table 3. Values measured by each protocol, for patients and controls, are shown in Figure 1. The URennes and manual T2* protocols showed good power of discrimination between patients and controls (AUC > 0.9). The $\mathrm{T} 2 *$ mapping protocol also had an AUC above

Table 3-Scan times, image analysis duration, and total time required to complete each of the MRI protocols evaluated.

\begin{tabular}{lccc}
\hline Protocol & Scan time & $\begin{array}{c}\text { Image analysis duration } \\
(\text { mean } \pm \text { SD) }\end{array}$ & $\begin{array}{c}\text { Average total } \\
\text { protocol time }\end{array}$ \\
\hline URennes & $109 \mathrm{~s}$ & $423 \pm 48 \mathrm{~s}$ & $530 \mathrm{~s}$ \\
Manual T2* & $11 \mathrm{~s}^{\dagger}$ & $308 \pm 39 \mathrm{~s}$ & $320 \mathrm{~s}$ \\
T2* mapping & $11 \mathrm{~s}^{\dagger}$ & $20 \pm 4 \mathrm{~s}$ & $30 \mathrm{~s}$ \\
T1 mapping & $5 \mathrm{~s}$ & $90 \pm 15 \mathrm{~s}$ & $100 \mathrm{~s}$ \\
\hline
\end{tabular}

${ }^{\dagger}$ Time for joint acquisition of the T2* mapping and manual T2* .
0.9 , although the T1 mapping protocol performed poorly, with an AUC of only 0.8 (95\% CI: 70-90.4\%), and differed significantly from the other protocols: URennes $(p$ $=0.008)$; manual $\mathrm{T}^{*}(p=0.038) ;$ and $\mathrm{T} 2^{*}$ mapping $(p$ $=0.031)$. The URennes, manual $\mathrm{T}_{2}^{*}$, and $\mathrm{T} 2 *$ mapping protocols had similar power to detect patients with elevated ferritin or transferrin saturation and clinically suspected hepatic iron overload (Figure 2).

Correlations among LIC measures obtained by the URennes, T2* mapping, and manual T2* protocols

To study the relationships among measures obtained by the URennes, $\mathrm{T} 2$ * mapping, manual $\mathrm{T} 2 *$, and $\mathrm{T} 1$ mapping protocols, we calculated the correlation coefficients. The results are shown in Figure 3. All measures showed a significant correlation among the protocols, and the correlation coefficients were above 0.9 for the URennes,
Figure 1. Values obtained using the URennes, manual T2*, T2* mapping, and T1 mapping protocols for patients and controls. C, controls; $\mathrm{P}$, patients.

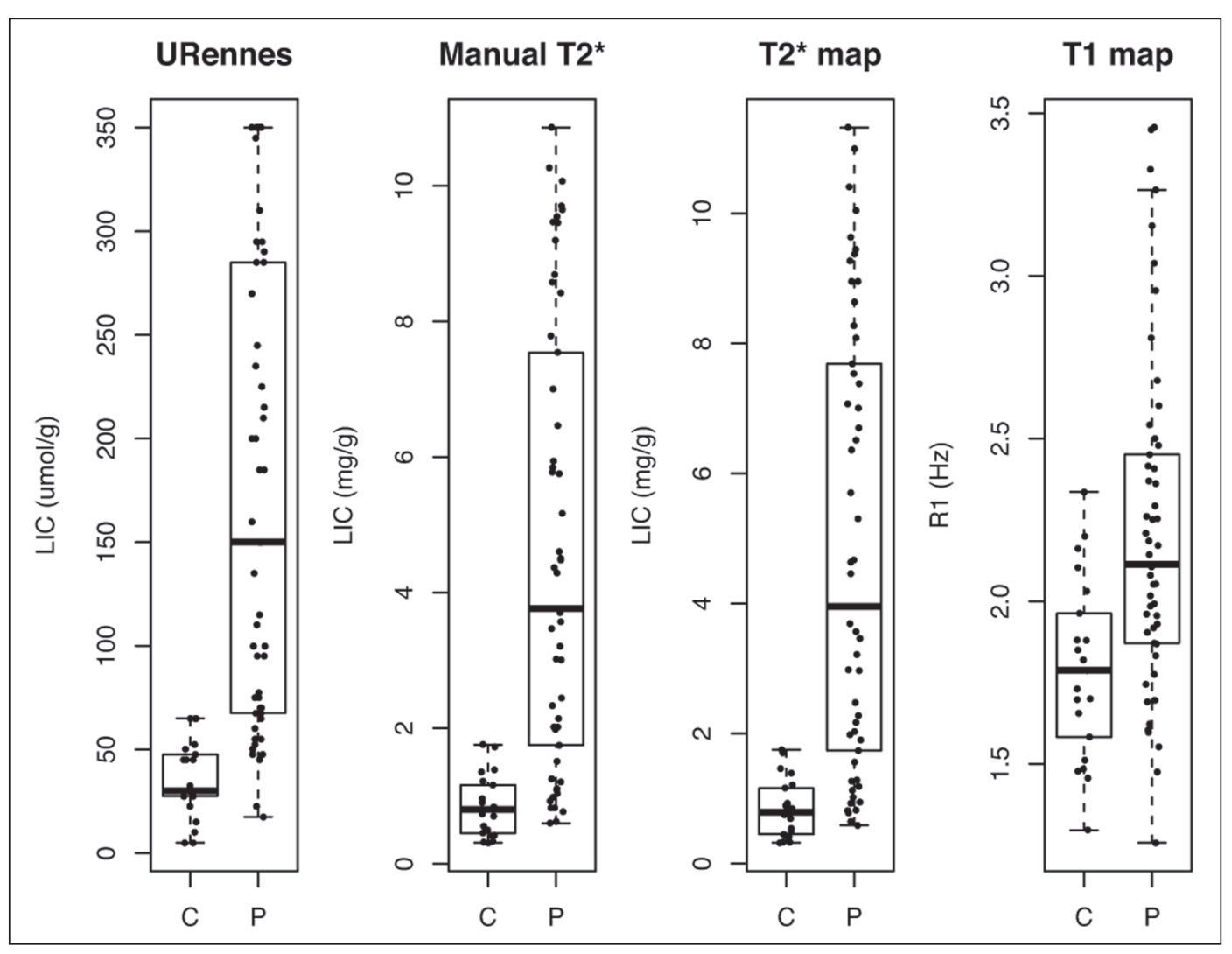


$\mathrm{T} 2 *$ mapping, and manual $\mathrm{T} 2 *$ protocols, although those associations were weaker when the URennes-measured LIC was above $350 \mu \mathrm{mol} \mathrm{Fe/g}$. The strongest correlation observed was between the $\mathrm{T} 2{ }^{*}$ mapping-measured LICs

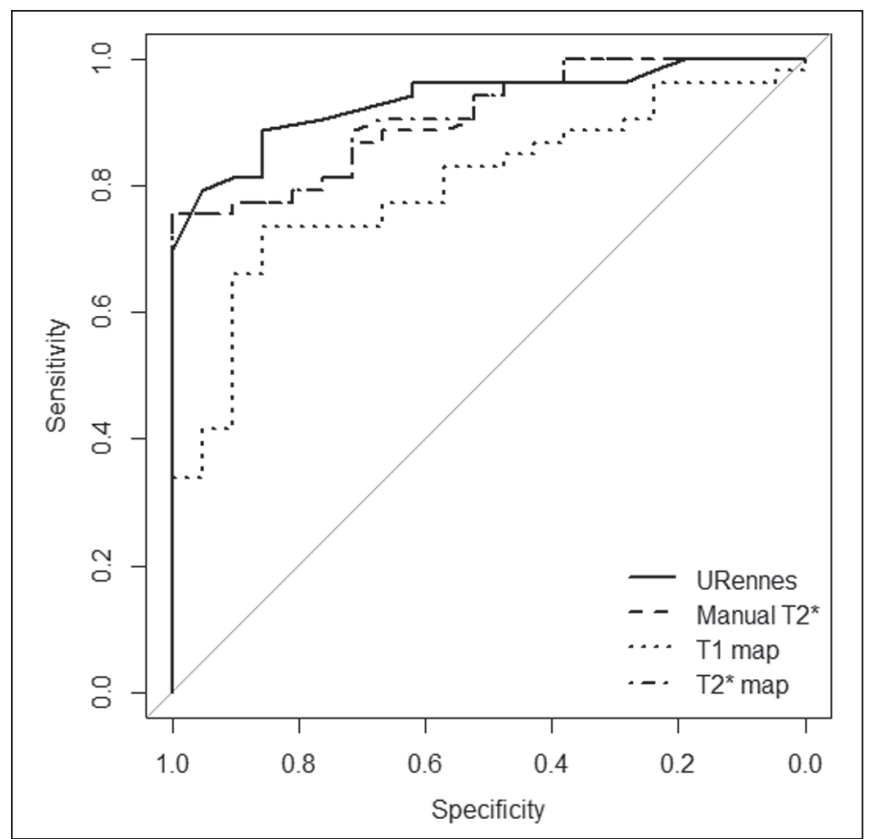

Figure 2. ROC curves using the URennes, manual T2*, T2* mapping, and T1 mapping protocols for separating patients and controls. The AUC $(95 \% \mathrm{Cl})$ was 0.934 (0.881-0.988) for URennes; 0.908 (0.844-0.972) for manual T2*; 0.80 (0.70-0.904) for T1 mapping; and 0.912 (0.849-0.974) for T2* mapping. The T1 mapping curve differs significantly from those of URennes $(p=$ $0.008)$, manual T2* $(p=0.038)$, and $\mathrm{T} 2 *$ mapping $(p=0.031)$. and those measured with the $\mathrm{T} 2 *$ manual protocol $(\mathrm{r}=$ 0.979). Correlations involving $\mathrm{R} 1$ values obtained with the T1 mapping protocol, although still significant, were lower, probably due to the great dispersion of $\mathrm{R} 1$ values. The T1 mapping protocol correlated most strongly with the URennes protocol $(\mathrm{r}=0.814 ; p<0.001)$.

\section{DISCUSSION}

In this study, we applied different methods of LIC estimation using $1.5 \mathrm{~T}$ MRI in a group of 53 patients and 21 controls and compared the results between manual and automatic methods. The main advantages of the mapping techniques are speed and ease of use. That was confirmed in our study, in which the time required for image acquisition/processing was found to be significantly shorter for the $\mathrm{T}^{*}$ mapping and $\mathrm{T} 1$ mapping protocols than for the URennes and manual $\mathrm{T}_{2}^{*}$ protocols.

Shortly after the conclusion of the data collection for this study in 2017 , the URennes published a study proposing a new method that employs a proton density technique, involving the use of magnitude images, and has produced quite promising results ${ }^{(9)}$. The authors of that study showed that the URennes method employed in the present study tends to overestimate LIC values and is susceptible to potentially serious errors if coils other than an antenna coil are employed. They recommended migrating to the Digital Imaging and Communication in Medicine MRQuantIF software that uses the Alústiza algorithm by default ${ }^{(21)}$, which controls the acquisition parameters ${ }^{(9)}$.

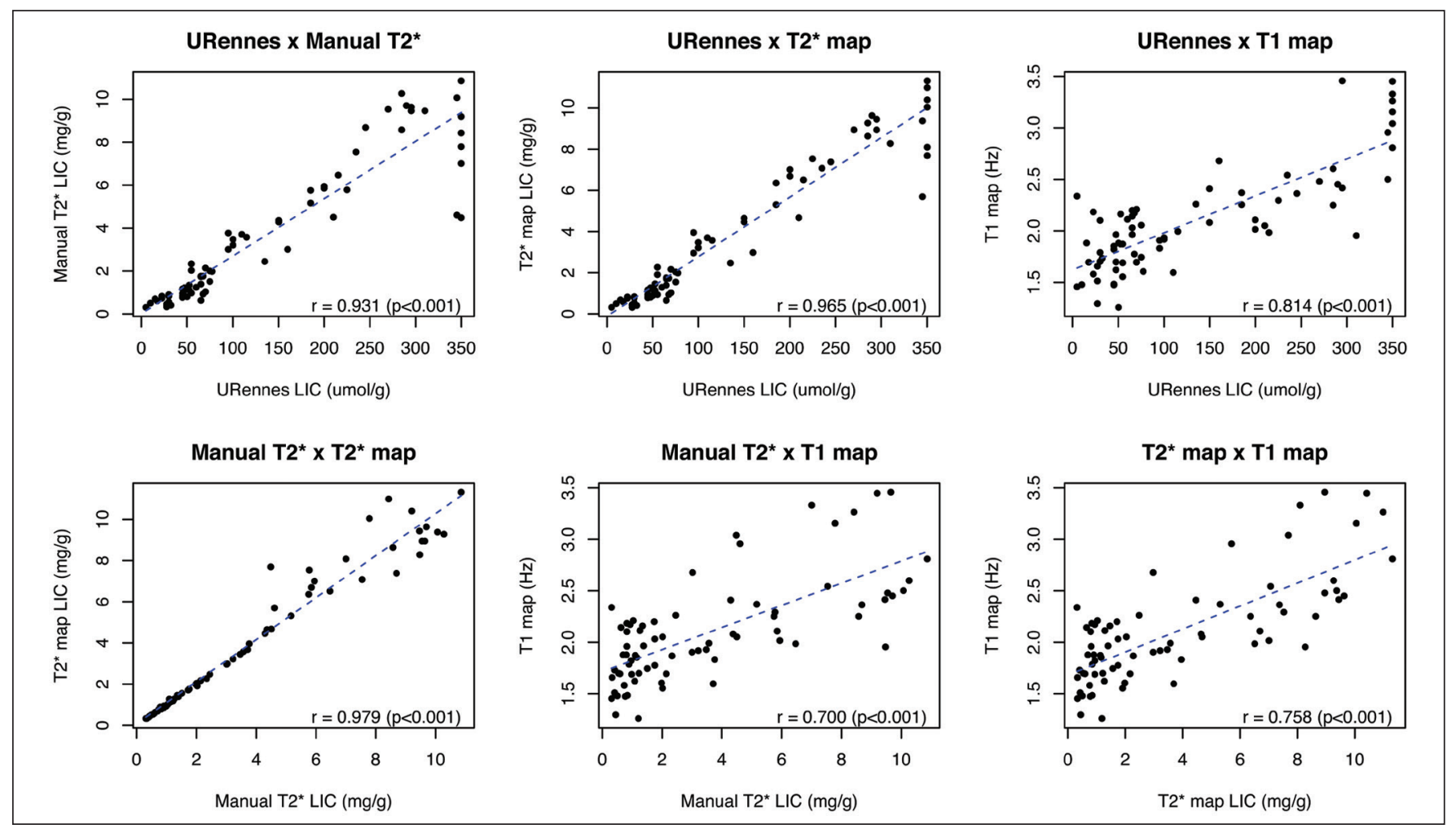

Figure 3. Correlations among the protocols. The blue line represents the fitted linear model. r, Spearman's correlation coefficient ( $p$-values refer to the correlation coefficient). 
Because that software would require the re-acquisition of imaging data using a different protocol, the remainder of the discussion will focus primarily on the manual $\mathrm{T} 2^{*}$, $\mathrm{T} 2 *$ mapping, and $\mathrm{T} 1$ mapping protocols.

In the present study, the level of interobserver agreement was good, the ICC being above 0.9 for all four protocols. The level of intraobserver agreement was also good, although the t-test showed a significant difference between measures obtained with the T1 mapping protocol. That is likely related to the higher dispersion of $\mathrm{R} 1$ values estimated using this method.

Native T1 mapping detects elevated levels of extracellular water, thus identifying fibrosis ${ }^{(18)}$, which is reflected in an increased T1 value. However, the presence of excess iron competes with this effect, reducing T1 (and conversely increasing $\mathrm{R} 1$ ). The most widely used $\mathrm{T} 1$ mapping sequence is based on the MOLLI technique. Described originally by Messroghli et al. ${ }^{(27)}$, it consists of a single-shot true fast imaging with steady-state precession sequence with acquisitions over different inversion time readouts, allowing for magnetization recovery of a few seconds after three to five readouts. The advantages of this sequence are its acquisition in only one relatively short breath-hold, the higher spatial resolution $(1.6 \times$ $2.3 \times 8 \mathrm{~mm}$ ), and the increased dynamic signal. T1 maps are generated automatically after MOLLI image acquisition, without the need for further post-processing, which accelerates image analysis. Similarly, in-line application of motion correction provides more accurate pixel-wise maps, avoiding artifacts due to respiratory motion. Torlasco et al. ${ }^{(28)}$ demonstrated that T1 mapping correlates better with cardiac and hepatic iron levels than does $\mathrm{T} 2$ * mapping. Despite those advantages, we found that $\mathrm{T} 1$ mapping showed the lowest ICC, the weakest correlation with the other methods, and the lowest AUC for differentiating patients from controls. Therefore, although we found a significant correlation with the R1 and LIC values estimated by the other methods, there is no clear evidence that T1 mapping could consistently estimate LIC values through the use of the protocol applied in this study. Nevertheless, there are many T1 sequences other than MOLLI that could be used-including shortened MOLLI, saturation recovery single-shot acquisition, saturation-pulse prepared heart-rate-independent inversionrecovery, and inversion time scout-each with different reference values. Further studies are needed in order to examine the relationship between $\mathrm{R} 1$ values and LIC.

There were strong correlations among the URennes, manual $\mathrm{T} 2 *$, and $\mathrm{T} 2 *$ mapping protocols regarding $\mathrm{LIC}$ estimation, and all correlations with the URennes protocol were significant, although the correlations among LIC measures were weaker when the LIC was above 15 $\mathrm{mg} \mathrm{Fe} / \mathrm{g}$. This corroborates current knowledge that there is saturation at $1.5 \mathrm{~T}$ with very high iron overload, consequently, the method cannot quantify LIC values greater than $375 \mu \mathrm{mol} / \mathrm{kg}(20.9 \mathrm{mg} / \mathrm{kg})$ and hence does not capture the entire relevant range of values ${ }^{(2)}$. For T2* calculations, depending on the MRI scanner gradient system, liver $\mathrm{T} 2 *$ can measure LICs only up to $40 \mathrm{mg} / \mathrm{g}^{(29)}$. That's because GRE sequences are inaccurate at higher iron overload levels ${ }^{(2,4,10,22,25)}$, given that the mGRE techniques employed are intrinsically limited when detecting rapidly decaying MRI signals. Nevertheless, higher LIC values can be measured with this method, because conventional mGRE techniques only start to become degraded during the measurement of signals with $\mathrm{T} 2{ }^{*}$ times $\leq 1$ $\mathrm{ms}$, corresponding to LIC values above approximately $25 \mathrm{mg} \mathrm{Fe} / \mathrm{g}$ liver (dry weight) at $1.5 \mathrm{~T}^{(10,25)}$. In contrast, d'Assignies et al. ${ }^{(5)}$, in a study comparing and validating the signal-intensity-ratio method and the $\mathrm{R} 2{ }^{*}$ method with liver biopsy at $3.0 \mathrm{~T}$, demonstrated that the biopsydetermined LIC correlates better with that determined by the R2* method than with that determined by the signalintensity-ratio method when the degree of iron overload is slight to moderate $(<130 \mu \mathrm{mol} / \mathrm{g})$. However, in patients with a high biopsy-determined LIC $(\geq 130 \mu \mathrm{mol} / \mathrm{g})$, the signal-intensity-ratio method correlates better.

The strongest correlation between methods was observed for that between the automated $\mathrm{T} 2 *$ mapping and manual $\mathrm{T} 2 *$ protocols. We find that interesting, because those two methods use the same image source for calculations, as well as because the time required for image acquisition and processing is approximately ten times shorter for the automated $\mathrm{T} 2 *$ mapping protocol than for the manual $\mathrm{T} 2 *$ protocol.

In the present study, we chose to use the conversion proposed by Hankins et al. ${ }^{(10)}$ for the manual T2* analysis. Those authors compared $\mathrm{R} 2 *$ values to the biopsy-determined LIC, using three different MRI methods, demonstrating that the estimations obtained with the shortest first TE correlated most strongly with the directly measured values ${ }^{(4,10)}$. Those values are easily calculated with a Microsoft ${ }^{\circledR}$ Excel spreadsheet, on which myocardial and hepatic iron concentrations can be estimated by inputting the mean SI values for each TE.

Parametric maps require specific sequences and software capable of performing the curve fits and generating maps without the need for manual user input. Unfortunately, there is great heterogeneity among the sequences and software implemented by different MRI equipment manufacturers, resulting in variation among estimated LIC measures. This is a major limiting factor for the use of this method in clinical practice. Nevertheless, studies have shown that $\mathrm{T} 2 *$ mapping can detect liver hemosiderosis $^{(30)}$ and can accurately identify high concentrations of iron ${ }^{(7)}$. In the present study, we found that $\mathrm{T} 2{ }^{*}$ mapping produced results similar to those of manual $\mathrm{T} 2 *$, with low levels intraobserver and interobserver variability.

Our study has some limitations. We employed only one 1.5 T MRI scanner, and it was therefore not possible 
to compare reproducibility between or among different devices. In addition, we included a limited number of subjects, especially in the control group. We also had no measure of serum ferritin in the control subjects and therefore cannot exclude the possibility of iron deposition, which can be seen in asymptomatic patients, in that group.

\section{CONCLUSION}

Our findings indicate that $\mathrm{T} 2{ }^{*}$ mapping of the liver is a promising new tool for the rapid diagnosis of hepatic iron overload, and that T1 mapping is less accurate for that purpose. Further studies are needed in order to improve understanding the value of T1 mapping in clinical practice and to propose changes to overcome intrinsic limitations of the manual $\mathrm{T} 2 *$ protocol in LIC estimation. There are various robust $\mathrm{T} 2 *$ methods that could be routinely used for estimating LIC.

\section{REFERENCES}

1. Wood JC, Ghugre N. Magnetic resonance imaging assessment of excess iron in thalassemia, sickle cell disease and other iron overload diseases. Hemoglobin. 2008;32:85-96.

2. Sirlin CB, Reeder SB. Magnetic resonance imaging quantification of liver iron. Magn Reson Imaging Clin N Am. 2010;18:359-81.

3. Wood JC. Magnetic resonance imaging measurement of iron overload. Curr Opin Hematol. 2007; 14:183-90.

4. Alústiza Echeverría JM, Castiella A, Emparanza JI. Quantification of iron concentration in the liver by MRI. Insights Imaging. 2012;3:173-80.

5. d'Assignies G, Paisant A, Bardou-Jacquet E, et al. Non-invasive measurement of liver iron concentration using 3-Tesla magnetic resonance imaging: validation against biopsy. Eur Radiol. 2018;28: 2022-30.

6. Christoforidis A, Perifanis V, Spanos G, et al. MRI assessment of liver iron content in thalassamic patients with three different protocols: comparisons and correlations. Eur J Haematol. 2009;82:38892.

7. Banerjee R, Pavlides M, Tunnicliffe EM, et al. Multiparametric magnetic resonance for the non-invasive diagnosis of liver disease. J Hepatol. 2014;60:69-77.

8. Wood JC, Zhang P, Rienhoff $\mathrm{H}$, et al. Liver MRI is more precise than liver biopsy for assessing total body iron balance: a comparison of MRI relaxometry with simulated liver biopsy results. Magn Reson Imaging. 2015;33:761-7.

9. Gandon Y. About MRQuantif software. [cited 2019 Mar 20]. Avail-

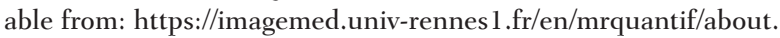

10. Hankins JS, McCarville MB, Loeffler RB, et al. R2* magnetic resonance imaging of the liver in patients with iron overload. Blood. 2009; 113:4853-5.

11. Gandon Y, Olivié D, Guyader D, et al. Non-invasive assessment of hepatic iron stores by MRI. Lancet. 2004;363:357-62.

12. Gandon Y. Hepatic iron \& fat. [cited 2020 March 19]. Available from: https://imagemed.univ-rennes l.fr/en/mrquantif/quantif/.

13. Fernandes JL, Siqueira MHA, Oliveira KTN, et al. Automated T2* maps of the heart and liver in comparison to manual analysis for iron overload assessment in the All Iron Detected (AID) multicenter study. J Cardiovasc Magn Res. 2015;17(Suppl 1):W18.
14. Maestrini V, Abdel-Gadir A, Herrey AS, et al. New generation cardiac parametric mapping: the clinical role of $\mathrm{T} 1$ and $\mathrm{T} 2$ mapping. [cited 2020 March 19]. Available from: https://static.healthcare.siemens. com/siemens_hwem-hwem_ssxa_websites-context-root/wcm/idc/ groups/public/@global/@imaging/@mri/documents/download/mday/ mjq2/ edisp/clinical_role_of_t1_and_t2_mapping-01 176232.pdf.

15. Wassmuth R, Prothmann M, Utz W, et al. Variability and homogeneity of cardiovascular magnetic resonance myocardial T2-mapping in volunteers compared to patients with edema. J Cardiovasc Magn Reson. 2013;15:27.

16. Pennell DJ, Udelson JE, Arai AE, et al. Cardiovascular function and treatment in $\beta$-thalassemia major: a consensus statement from the American Heart Association. Circulation. 2013;128:281-308.

17. Fernandes JL, Strecker R, Greiser A, et al. Myocardial T1-mapping: techniques and clinical applications. [cited 22020 March 19]. Available from: https://static.healthcare.siemens.com/siemens_hwemhwem_ssxa_websites-context-root/wcm/idc/groups/public/@global/@ imaging/@mri/documents/download/mdaw/mte5/ edisp/myocardial_ t1_mapping_techniques_clinical_applications-001 18083.pdf.

18. Moon JC, Messroghli DR, Kellman P, et al. Myocardial T1 mapping and extracellular volume quantification: a Society for Cardiovascular Magnetic Resonance (SCMR) and CMR Working Group of the European Society of Cardiology consensus statement. J Cardiovasc Magn Reson. 2013;15:92.

19. Ernst O, Rose C, Sergent G, et al. Hepatic iron overload: quantification with MR imaging at 1.5 T. AJR Am J Roentgenol. 1999; 172:1141-2.

20. Castiella A, Alústiza JM, Emparanza JI, et al. Liver iron concentration quantification by MRI: are recommended protocols accurate enough for clinical practice? Eur Radiol. 2011;21:137-41.

21. Alústiza JM, Emparanza JI, Castiella A, et al. Measurement of liver iron concentration by MRI is reproducible. Biomed Res Int. 2015;2015:294024.

22. Anderson LJ, Holden S, Davis B, et al. Cardiovascular T2-star (T2*) magnetic resonance for the early diagnosis of myocardial iron overload. Eur Heart J. 2001;22:2171-9.

23. St Pierre TG, Clark PR, Chua-anusorn W, et al. Noninvasive measurement and imaging of liver iron concentrations using proton magnetic resonance. Blood. 2005;105:855-61.

24. Garbowski MW, Carpenter JP, Smith G, et al. Biopsy-based calibration of $\mathrm{T} 2 *$ magnetic resonance for estimation of liver iron concentration and comparison with R2 Ferriscan. J Cardiovasc Magn Reson. 2014;16:40.

25. Henninger B, Zoller $\mathrm{H}$, Rauch $\mathrm{S}$, et al. R2* relaxometry for the quantification of hepatic iron overload: biopsy-based calibration and comparison with the literature. Rofo. 2015;187:472-9.

26. Buckens CF, de Jong PA, Mol C, et al. Intra and interobserver reliability and agreement of semiquantitative vertebral fracture assessment on chest computed tomography. PloS One. 2013;8:e71204.

27. Messroghli DR, Radjenovic A, Kozerke S, et al. Modified LookLocker inversion recovery (MOLLI) for high resolution T1 mapping of the heart. Magn Reson Med. 2004;52:141-6.

28. Torlasco C, Cassinerio E, Roghi A, et al. Role of T1 mapping as a complementary tool to $\mathrm{T} 2 *$ for non-invasive cardiac iron overload assessment. PLoS One. 2018;13:e192890.

29. Wood JC. Estimating tissue iron burden: current status and future prospects. Br J Haematol. 2015;170:15-28.

30. Cassinotto C, Feldis M, Vergniol J, et al. MR relaxometry in chronic liver diseases: comparison of T1 mapping, T2 mapping, and diffusion-weighted imaging for assessing cirrhosis diagnosis and severity. Eur J Radiol. 2015;84:1459-65. 